\section{Prémio Nobel da Química 2014}

MICROSCOPIA ÓPTICA DE SUPER-RESOLUÇÃO: DA MICROSCOPIA À NANOSCOPIA

O Prémio Nobel da Química 2014 foi atribuído a Stefan W. Hell (Max Planck Institute for Biophysical Chemistry e German Cancer Research Center, Alemanha), Eric Betzig (Howard Hughes Medical Institute, EUA) e William E. Moerner (Stanford University, EUA), pelo desenvolvimento da microscopia de fluorescência de super-resolução [1], que tornou possível a obtenção de imagens ópticas à escala dos nanómetros $\left(10^{-9} \mathrm{~m}\right)$, isto é, muito abaixo do limite de difracção da luz.

A invenção do microscópio, algures entre o século XII e o final do século XVI, é de origem ainda controversa, sendo

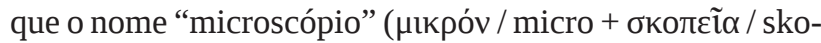
pei / instrumento de observação) foi cunhado por Giovanni Faber em 1625, para designar o microscópio composto de Galileo Galilei, seu amigo e colega da Academia dei Lincei em Roma. A microscopia óptica evoluiu muito desde os seus primórdios, mas sempre limitada pelo aparentemente incontornável limite da difracção da luz, formulado por Ernst Abbe (1873) e Lord Rayleigh (1896) [2,3], que pode ser expresso na forma da lei de Abbe: "(the) minimum resolving distance is related to the wavelength of light divided by the Numeric Aperture, which is proportional to the angle of the light cone formed by a point on the object, to the objective”. Grosso modo, este limite significa que é impossível distinguir dois elementos numa estrutura que distem entre si (no plano horizontal, xy) menos que cerca de metade do comprimento de onda da radiação usada, e ainda mais, no plano longitudinal (z). Ou seja, a resolução espacial da imagem em microscopia óptica (luz visível: $400-800 \mathrm{~nm})$ é limitada a cerca de $0,3 \mu \mathrm{m}\left(0,3 \times 10^{-6} \mathrm{~m}\right)$.

Uma forma de melhorar a resolução espacial é utilizar radiação de menor comprimento de onda, o que foi conseguido substituindo a luz visível por um feixe de electrões, que têm associados comprimentos de onda sub-nanométricos, permitindo à microscopia electrónica uma resolução que pode chegar ao nível atómico. No entanto, as condições extremas necessárias para obter uma imagem por microscopia electrónica (correntes muito altas, vácuo, etc.), limitam severamente a sua utilização em amostras sensíveis, como células vivas, materiais poliméricos, etc.

Estas limitações alimentaram o interesse em encontrar formas de contornar a lei de Abbe. O Prémio Nobel da Química 2014 veio precisamente galardoar três cientistas que o fizeram com sucesso, desenvolvendo a microscopia de fluorescência de super-resolução, ou nanoscopia, que tornou possível a obtenção de imagens com luz visível à escala dos nanómetros. Como base, utilizaram a microscopia óptica de fluorescência, que consiste em observar somente a luz emitida por moléculas fluorescentes (nomeadamente proteínas fluorescentes, algumas das quais desenvolvidas por Roger Tsien, Prémio Nobel da Química em 2008), que ao ocuparem posições conhecidas na amostra, permitem obter a imagem apenas das estruturas onde se localizam.
Eric Betzig e William Moerner, trabalhando independentemente, estabeleceram os princípios da microscopia de molécula única, uma técnica que permite determinar a localização de moléculas individuais, mesmo que mais próximas que o limite de difracção da luz. Qual é o truque? Em vez de tentar detectar moléculas muito próximas no espaço, Betzig e Moerner, conceberam uma forma de as separar no tempo, fazendo com que apenas um pequeno número aleatório de moléculas emita luz de cada vez que a amostra é varrida com o laser de excitação. A imagem da amostra é reconstruída repetindo este procedimento milhares de vezes e sobrepondo os resultados.

Moerner foi o primeiro a detectar uma única molécula fluorescente [4], tendo mais tarde descoberto que uma variedade da proteína verde fluorescente (green fluorescent protein, GFP) podia ter a sua emissão ligada e desligada: a proteína emitia quando excitada com luz verde de $488 \mathrm{~nm}$, apagando-se para não voltar a emitir [5]. No entanto, exposta a luz azul de $405 \mathrm{~nm}$, a proteína era reactivada e podia ser novamente excitada com luz de $488 \mathrm{~nm}$. Estas moléculas fotoactiváveis estão na base da microscopia de super-resolução PALM (photoactivated localization microscopy), inventada por Betzig [6] e desenvolvida com Harald Hess [7] em 2006 (Figura 1), a que se seguiram outros métodos semelhantes (STORM, fPALM, etc.).

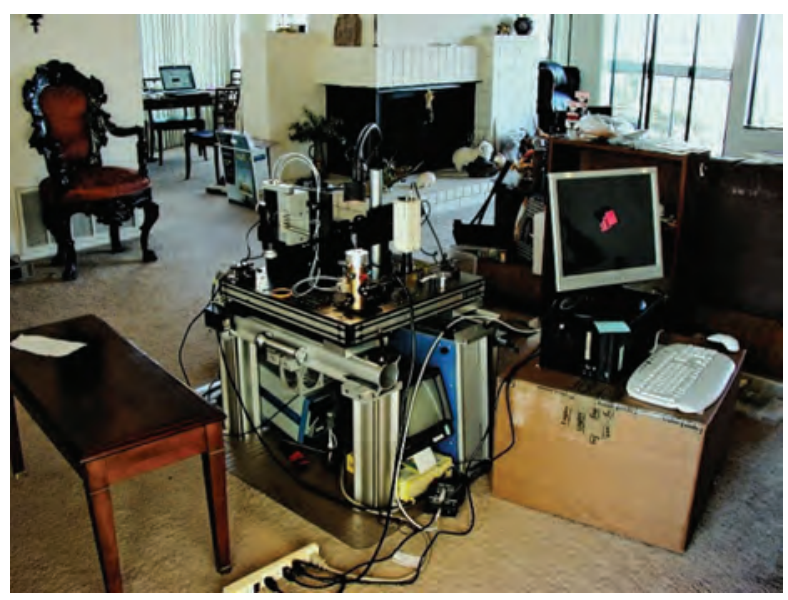

Figura 1 - Primeiro microscópio PALM, construído por Eric Betzig e Harald Hess (em casa deste último). (Direitos de autor 2014 Howard Hughes Medical Institute)

O método inventado por Stefan Hell, a microscopia de depleção por emissão estimulada (stimulated emission depletion, STED), dispensa a recolha e sobreposição de milhares de imagens, necessária aos outros métodos de super-resolução. No seu método, Stephen Hell utiliza dois feixes laser concêntricos. Um dos lasers é utilizado para excitar as moléculas fluorescentes, o outro, com um perfil radial de intensidade em forma de 'donut', provoca a emissão estimulada de todas as moléculas que não se encontram num volume nanométrico no centro do feixe, apagando-as e permitindo detectar apenas as restantes moléculas neste volume. Varrendo a amostra ponto a ponto é possível obter uma imagem com resolução manométrica [8-10].

Foram precisamente os avanços mais recentes na microscopia STED que trouxeram Stefan Hell a Lisboa no pas- 
sado mês de Julho (Figura 2), como orador convidado das 4. ${ }^{\text {as }}$ Jornadas Ibéricas de Fotoquímica (4’JIF) organizadas pelo Grupo de Fotoquímica da Sociedade Portuguesa de Química com a colaboração da Real Sociedade Espanhola de Química (http://4jif.eventos.chemistry.pt). Progressos recentes como a aquisição multiponto por varrimento paralelo (STED RESOLFT) e o desenvolvimento de novos corantes para STED prometem tornar a nanoscopia uma técnica corrente de laboratório.

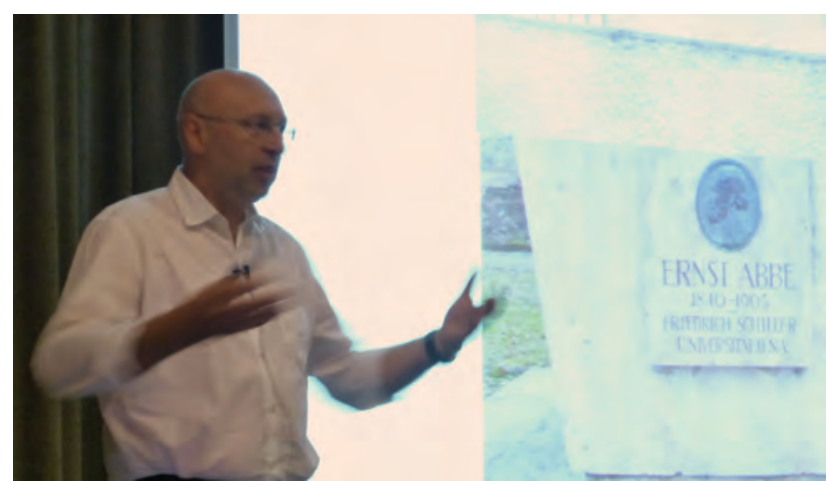

Figura 2 - Stefan Hell nas 4. ${ }^{\text {as }}$ Jornadas Ibéricas de Fotoquímica (4’JIF) em Lisboa (Julho 2014, http://4jif.eventos.chemistry.pt)

Apesar de recentes, as técnicas de microscopia de super-resolução, já permitiram avanços notáveis, em especial nas ciências biológicas. Por exemplo, em Julho, Stefan

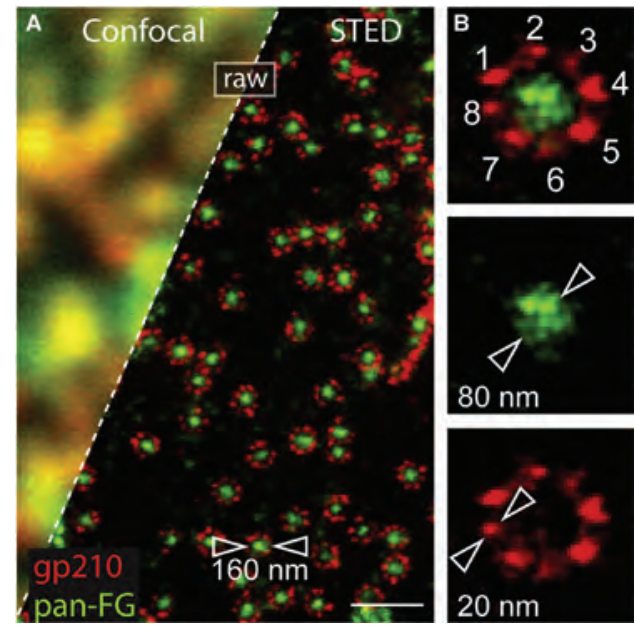

Figura 3 - Imagem STED de complexos proteicos de anfíbio (Xenopus). (A) A imagem STED revela as subunidades do anel octamérico dos complexos de poro nucleares (nuclear pore complexes, NPC), indistinguíveis por microscopia confocal (escala $500 \mathrm{~nm}$ ). (B) Nas unidades individuais de NPC são visíveis os oito homodímeros [11]. (Direitos de autor 2013 Elsevier)
Hell mostrou em Lisboa imagens da estrutura de octameros proteicos dos complexos de poro nucleares (Figura 3) e da formação de sinapses por células vivas do sistema nervoso; Moerner e outros obtiveram imagens de células mostrando a agregação de proteínas relacionadas com as doenças de Parkinson, Alzheimer e Huntington; Betzig observou proteínas individuais durante a fertilização de óvulos e a sua divisão em embriões, etc. O potencial das técnicas de nanoscopia desenvolvidas pelos prémios Nobel da Química de 2014 é imenso. É agora possível pela primeira vez, não só visualizar os componentes do interior de organelos celulares, mas ainda localizar proteínas específicas e seguir as suas interacções dentro de células vivas, isto é, observar o funcionamento de moléculas individuais no interior das células e assim perceber melhor o funcionamento da vida.

\section{REFERÊNCIAS}

[1] “The Nobel Prize in Chemistry 2014” http://www.nobelprize.org/nobel_prizes/chemistry/laureates/2014 (Nobel Media AB 2014, acedido a 29-10-2014)

[2] E. Abbe, Archiv fur mikroskopische Anatomy 9 (1873) 413$-418$

[3] L. Rayleigh, Philos. Mag. 42 (1896) 167-195

[4] W.E. Moerner, L. Kador, Phys. Rev. Lett. 62 (1989) 2535$-2538$

[5] R.M. Dickson, A.B. Cubitt, R.Y. Tsien, W.E: Moerner, Nature 388 (1997) 355-358

[6] E. Betzig, Opt. Lett. 20 (1995) 237-239

[7] E. Betzig, G.M. Patterson, R. Sougrat, O.W. Lindwasser, S. Olenych, J.S., Bonifacino, M.W. Davidson, J. Lippincott-Schwartz, H.F. Hess, Science 313 (2006) 1642-1645

[8] S.W. Hell, J. Wichman, Opt. Lett. 19 (1994) 780-782

[9] S.W. Hell, M. Kroug, Appl. Phys. B 60 (1995) 495-497

[10] T.A. Klar, S. Jakobs, M. Dyba, A. Egner, S.W. Hell, Proc. Natl. Acad. Sci. USA. 97 (2000) 8206-8210

[11] F. Gottfert, C.A. Wurm, V. Mueller, S. Berning, V.C. Cordes, A. Honigmann, S.W. Hell, Biophysical Journal 105 (2013) L01-L03

José Paulo Farinha (farinha@tecnico.ulisboa.pt)

\section{Sociedade Portuguesa de Química}

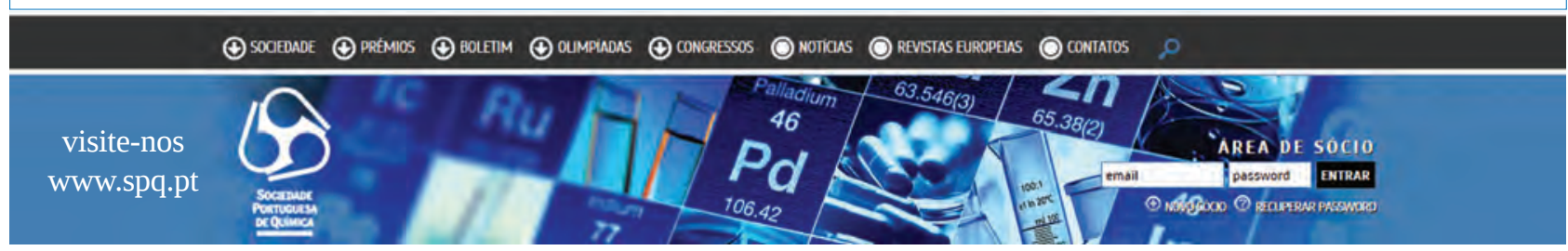

